\title{
Um salto para a performatividade: sentidos atribuídos à qualidade da educação
}

Talita Vidal Pereira*

Luciana Velloso**

\section{Resumo}

Neste artigo procuramos discutir os efeitos da instauração da cultura da performatividade (BALL, 2004) nas escolas da rede municipal de ensino na cidade do Rio de Janeiro, a partir da implementação do Projeto "Salto de Qualidade na Educação Carioca". Trata-se de um projeto de intervenção que envolve múltiplas ações desenvolvidas ao longo de 2009 e que tem como objetivo a melhoria da qualidade do ensino oferecido às crianças. Com base na teoria do discurso (LACLAU; MOUFFE, 2004) procuramos problematizar os sentidos atribuídos à qualidade. A análise foi desenvolvida a partir das declarações dos gestores da administração municipal, que através da mídia impressa procuram impor os sentidos que atribuem à educação de qualidade. Analisamos também os relatos colhidos em entrevistas em uma escola da rede envolvida no projeto.

Palavras-chave: Performatividade. Cultura escolar. Teoria do Discurso.

\section{A jump for performativity: meanings attributed to the quality of education Abstract}

In this article we seek to argue the effects of introducing the culture of performativity (BALL, 2004) in the municipal schools of the city of Rio de Janeiro, with the implementation of the Project "Leap of Quality Education in Rio". This is an intervention project that involves multiple actions developed during the year of 2009, with the objective of improving the quality of the education offered to children. Based on discourse theory (LACLAU; MOUFFE, 2004), we question the meanings attributed to quality. The analysis was developed from the statements

\footnotetext{
* Doutora em Educação, Universidade do Estado do Rio de Janeiro (UERJ); professora substitua UERJ; Professora Docente da Secretaria de Estado de Educação do Rio de Janeiro. E-mail: p.talitavidal@gmail.com

** Doutoranda em Educação, UERJ; Professora Substituta da UERJ. E-mail: lucianavss@gmail.com
} 
of managers of the municipal administration, who, through the printed media, try to impose the meanings they attribute to quality education. We also analyzed the accounts collected in a school network involved in the project.

Keywords: Performativity. School culture. Discourse theory.

\section{Un salto hacia la performatividad: sentidos atribuidos a la calidad de la educación. Resumen}

Este artículo tiene por objeto discutir los efectos de la instauración de la cultura de la performatividad (BALL, 2004) en las escuelas municipales de la ciudad de Río de Janeiro, a partir de la implementación del Proyecto denominado SALTO DE CALIDAD EN LA EDUCACIÓN CARIOCA. Se trata de un proyecto de intervención que involucra múltiples acciones desarrolladas a lo largo de 2009 y que tiene como objetivo la mejora de la calidad de la enseñanza ofrecida a los alumnos. Con base en la teoría del discurso (LACLAU y MOUFFE, 2004) se busca problematizar los sentidos atribuidos a la calidad. El análisis se desarrolló a partir de las declaraciones de los gestores de la administración municipal, que a través de los medios impresos buscan imponer los sentidos que le atribuyen a la educación de calidad. Se analizan también los relatos recogidos a través de entrevistas hechas en una escuela de la red que participa en el proyecto.

Palabras clave: Performatividad. Cultura escolar. Teoría del Discurso.

A elaboração deste artigo foi motivada pela necessidade de discutirmos, a partir da apropriação dos referenciais teóricos que temos utilizado em nossos estudos, a situação de insegurança e instabilidade que temos constatado nas escolas em que desenvolvemos nossas pesquisas.

Neste sentido, queremos destacar que, na perspectiva em que procuramos compreender a dinâmica de funcionamento das instituições escolares, a instabilidade é tida como uma característica importante e produtiva, dado que concebemos a escola como espaço-tempo (MACEDO, 2003) em que diferentes culturas circulam (TURA, 2002), dando pouca margem para a consolidação de certezas. No entanto, o que nos causa estranhamento no movimento e comportamentos identificados é a origem e a natureza dos motivos que têm levado ao crescimento da insegurança e da instabilidade. Entendemos que estes sentimentos são consequência das ações de intervenção pedagógica e administrativa propostas pelos organismos centrais, no caso a Secretaria Municipal de Educação do Rio de Janeiro (SME/Rio).

Outra ressalva diz respeito ao referencial teórico metodológico que adotamos e que permite que analisemos este processo para além de uma perspectiva verticalizada que tende a privilegiar os aspectos da macro-política que destacam a centralidade do Estado na definição e produção das políticas educacionais. 
Assumimos o conceito de discurso desenvolvido por LACLAU $(1996 ; 2005)$ o que nos permite pensar que os discursos produzem realidade. Dessa forma, operamos com a compreensão de que as políticas educacionais são discursos que produzem sentidos sobre o que a escola é e o que ela deveria ser. No entanto, Laclau e Mouffe (2004) concebem essa produção como um processo contingente e precário: uma operação discursiva em que determinados sentidos precisam ser preenchidos de forma que possam ser completamente universalizados. Para os autores, esse esforço de universalização é fundamental para a constituição hegemônica de um discurso. No entanto, o preenchimento de sentidos articulados em um discurso será sempre parcial. Por um lado, devido ao corte antagônico que constitui um limite que impede a completa proliferação de sentidos de um dado discurso , (tudo aquilo que está além dos limites de um sistema discursivo não pode produzir sentidos no interior do mesmo); por outro lado, porque a universalização de um discurso implica em processo de negociação (diferentes sentidos entram em relação e se modificam incessantemente, impedindo que um único significado, atribuído a um determinado objeto particular, possa ser definitivamente universalizado).

É nesta perspectiva que nos apropriamos da abordagem do ciclo de políticas proposta por Bowe, Ball e Gold (1992) - um referencial de análise que busca captar o dinamismo presente nas políticas educacionais desde o seu processo de concepção até a sua concretização no cotidiano da escola. Isto é possível na medida em que assumimos a política como discurso que se opera no sentido de tentar fixar sentidos conformando determinadas identidades. Trata-se de uma perspectiva que abre a possibilidade de analisar as políticas educacionais para além de mera imposição do Estado, pois concebe sua produção como processo de disputas e embates. 0 discurso que expressa a política é assumido como tentativa de fechamento que busca fixar um único sentido possível de ser atribuído à mesma. No entanto, a constituição de hegemonia dessa política implica em concebê-la como discurso aberto a múltiplas negociações que produzirão, necessariamente, sentidos diversos.

É deste modo que procuramos compreender as formas pelas quais políticas educacionais que expressam uma cultura da performatividade (BALL, 2004) vão se instaurando nas escolas e de que maneira ela procura alterar o funcionamento dessas instituições. Ou seja, se o discurso constitui realidade, trata-se de investigar que sentidos de escola estão sendo produzidos e que identificações estão sendo possibilitadas, como forma de atender a hegemonização de um projeto de mundo que atenda às demandas que as propostas anunciam atender.

As politicas educacionais refletem diferentes objetivos da educação que, por sua vez, são propostos como alternativas para atender às demandas de formação em função de transformações no âmbito da política e da economia, tanto nacional como internacional e que ganham força nas reivindicações de diversos setores da sociedades. É nessa pers- 
pectiva que buscamos compreender o papel centralizador que o Estado passa a assumir no desenvolvimento de políticas que têm se caracterizado pela sua interferência, com tentativas de normatização e regulamentação do cotidiano das escolas.

Entendemos que essa orientação se dá no âmbito do processo de reestruturação econômica que o mundo passa a experimentar como uma tendência, a partir da segunda metade do século XX. 0 esgotamento de um modelo de produção capitalista e o surgimento de novas relações entre economia, política e sociedade levaram a um processo de esvaziamento do modelo de Estado-Nação, que foi perdendo suas características de Estado provedor passando a assumir um papel marcadamente regulador. Trata-se de um modelo de Estado organizado para controlar metas e desempenhos previamente estabelecidos, que passou a ter a sua capacidade de intervenção no sentido de responder às demandas sociais, ainda mais limitadas.

Dentre os elementos que podem caracterizar o processo de reestruturação econômica, Burbulles e Torres (2004) listam a flexibilização do trabalho com intensificação da competitividade que, aliada às mudanças provocadas pelos altos níveis de avanço tecnológico, em especial na informática, alteram profundamente os processos de trabalho, determinando a exigência de novas competências requeridas da mão-de-obra.

Por outro lado, a dinâmica de reorganização do capital está relacionada também ao movimento de expansão dos processos de mercantitilização que passaram a incorporar, cada vez mais, setores até então postos fora do mercado. É o que acontece com os serviços sociais como a educação, por exemplo, que é assumida, cada vez mais, como valor de troca, em detrimento do seu valor de uso. Trata-se de um bem privado, cujo aceso garante determinado status social. Seu valor passa a se situar "na troca por emprego, prestígio e conforto" (MACEDO, 2002, p. 136).

É nesta perspectiva que nos propomos analisar a constituição do discurso educacional que, neste contexto de mudanças, reafirma a educação como possibilidade de inclusão tanto para os sujeitos, quanto para as nações, na medida em que dela resultaria maiores possibilidades de desenvolvimento. Um discurso em defesa da qualidade da educação que se propaga e hegemoniza, entendendo a constituição de hegemonia como uma operação discursiva permanente, contingente e provisória em que são articuladas demandas diferenciadas (LACLAU, 2005).

Apoiada nas teorizações de Laclau e Lopes (2010) tem procurado entender a ideia de qualidade da educação como um significante vazio. Isso porque, segundo o autor, um significante vazio é um significante que, no processo das práticas articulatórias, assume a posição de uma demanda maior capaz de articular outras inúmeras e diferentes demandas presentes no campo da discursividade. Para Laclau (2005), a saturação de sentidos de um significante é condição necessária para a constitui- 
ção de hegemonia de um discurso, em que sentidos são produzidos, negociados e recontextualizados num esforço incessante de fixação. No entanto, essa proliferação de sentidos acaba por esvaziá-lo de significado.

Assumindo esse entendimento, Lopes (2010) assume a ideia de qualidade da educação como um significante saturado de sentidos que torna possivel a hegemonia de um discurso em sua defesa, articulando demandas diferenciadas. Trata-se de pensar os processos discursivos em que "a educação se tornou objeto de um consenso (hegemonia) quanto a seu papel constitutivo de uma nova sociabilidade assentada no vocabulário republicano da cidadania ou no vocabulário liberal da competência técnica e autonomia individual" (BURITY, 2010, p. 7).

É nessa perspectiva que buscamos entender os diferentes sentidos atribuídos à ideia de qualidade da educação, inclusive aqueles em que ela está associada a uma concepção utilitária concebida a partir de uma cultura competitiva, característica da dinâmica do mercado. A nosso ver, a constituição desse discurso se dá com o objetivo de forjar um projeto cultural em que a ideia de mercado como regulador das relações sociais possa ser naturalizada, o que implica na necessidade de constituição de novas identidades mais adequadas à reprodução da nova ordem que se pretende estabelecer como hegemônica.

Discutindo as implicações das transformações econômicas, políticas e sociais em curso nas instituições do setor público e na vida dos cidadãos. Ball (2004) ressalta o uso da performatividade como uma tecnologia política que tem favorecido essas mudanças e nos fornece um elemento importante para entender como essas transformações se processam no cotidiano das escolas. Para o autor, a performatividade se sustenta em um discurso que afirma a superioridade da eficácia do privado sobre o público e "funciona para empurrar as instituições do setor público à maior convergência com o setor privado" (BALL, 2004, p. 1117), organizando "um sistema de recompensas e sanções baseado na competição" (BALL, 2004, p. 1107).

Dessa forma, a performatividade pode ser sintetizada como um principio de eficácia que atua como uma forma de controle indireto ou à distância, que substitui a intervenção e a prescrição pelo estabelecimento de objetivos, pela prestação de contas, pela comparação e pela avaliação de desempenho (DIAS, 2009).

No entanto, o próprio Ball (2004) alerta para o fato de que, na cultura da performatividade, as escolas são encorajadas a se reformularem em uma direção que nem sempre acontece de forma a atender aos objetivos previamente definidos.

Esta observação nos remete a duas questões. A primeira diz respeito à compreensão de que todo processo de produção de uma política implica em tradução, 
negociação e práticas que se reconfiguram em diferentes contextos (BOWE; BALL; GOLD, 1992). A segunda, que decorre da primeira, diz respeito à compreensão de que a intensificação dos mecanismos de controle e reafirmação do discurso da performatividade são estratégias de saturação de um determinado sentido atribuído à política. São tentativas de limitar a emergência de outros sentidos possiveis de serem a ela atribuídos. Trata-se de um processo de constituição de hegemonia como prática articuladora de sentidos (LACLAU; MOUFFE, 2004).

Ball (2004) também destaca a privatização como uma outra tecnologia utilizada nos processos de alteração das relações escolares. Citando o caso inglês, o autor destaca a emergência das Parcerias Público-Privado como efeito da disseminação de um discurso "que celebra a 'superioridade' da gestão do setor privado em 'parceria' com o Estado, sobre e contra a modalidade conservadora, burocrática e apática de administração do setor público" (BALL, 2004, p. 1117).

Se na Inglaterra esse movimento é mais acirrado, envolvendo o setor privado na construção e na gestão de escolas, no Brasil esse processo assume outras configurações como o incentivo às ações voluntárias (Parceiros da Educação', por exemplo), e a contratação, por parte do setor público, de consultorias privadas nas mais diferentes áreas.

Realizando nossas pesquisas em escolas da rede municipal de ensino da cidade do Rio de Janeiro, foi possível perceber essas tendências, em especial na proposta do Projeto "Salto de Qualidade na Educação Carioca" (SOEC) que tomamos como referência para desenvolver este artigo. Trata-se de um projeto integrado de intervenção na rede municipal de ensino e que envolve múltiplas ações desenvolvidas pela SME/Rio ao longo de 2009, após o início da atual gestão municipal. Como base em requisitos que define como condições para a eficiência de uma política pública, a SME/Rio lança o Projeto SOEC com o objetivo de "melhorar a qualidade do ensino oferecido às crianças do Rio de Janeiro" (RIO DE JANEIRO, 2009). A discussão em torno da qualidade da educação no Município ganhou destaque no processo eleitoral mobilizando uma parcela significativa da população insatisfeita com os níveis de aprendizagem apresentados pelos alunos. No entanto, cabe questionar sobre os sentidos atribuídos a uma qualidade desejável da educação, assumindo os inúmeros sentidos a ela atribuídos.

Neste artigo, tomamos como material de análise, além de matérias de jornais, 0 conteúdo do site da SME/Rio (RIO DE JANEIRO, 2009) que tem cumprido importante canal de comunicação entre os gestores centrais e os profissionais das escolas. 0 privilégio que os gestores atribuem a esse canal da divulgação das propostas e 0 referencial teórico metodológico que assumimos nos autoriza a assumi-los como discursos que produzem sentidos de qualidade que, ao chegar até as escolas, nelas

A entidade defende um modelo de parceria entre empresários e escolas públicas para atuação em ações físico-estruturais, de gestão, pedagógicas e de integração escola-comunidade. 
serão negociados. Utilizamos também declarações dos gestores da administração municipal na mídia impressa que buscam reforçar e fixar sentidos. Também analisamos situações que observamos em uma das escolas da rede municipal, em que realizamos nosso estudo e que foi selecionada para integrar o projeto.

Vamos designar a escola que selecionamos como Escola Amanhã (EA). Ela está situada no contexto do Complexo do Alemão, que envolve cinco bairros da Zona Norte do Rio de Janeiro (Penha, Inhaúma, Bonsucesso, Ramos e Olaria). Trata-se de uma região de periferia que já foi industrial é hoje o maior cemitério de fábricas da cidade. A posição geográfica da Escola a levou a fazer parte da lista das cento e cinquenta Escolas do Amanhã.

0 projeto Escolas do Amanhã é outra ação dentro do SOEC, destinada ao atendimento especial às unidades escolares localizadas nas áreas mais conflagradas pela violência na cidade. Divulgado pela SME/Rio como "Primeira política pública exclusiva para as escolas em áreas de risco na cidade".

A escola funciona em dois turnos e atende alunos do primeiro ao quinto ano do Ensino Fundamental e da Educação Infantil. Seu entorno não pode ser considerado como um ambiente ideal e favorável: situada em uma região considerada como de baixo Índice de Desenvolvimento Humano (IDH), a escola se localiza em uma área de grande risco. Em umas das primeiras visitas, foi possivel constatar a presença ostensiva das tropas do Exército, dando às ruas um aspecto de "praça de guerra", ainda que fosse possivel perceber um clima de naturalidade entre os moradores que circulavam pelas ruas com aparente tranquilidade.

Este cenário foi determinante para a inclusão da escola no projeto. No entanto, apesar de todas as vicissitudes externas, a EA funciona em um prédio bem conservado em meio a um cenário conturbado. Contudo, as precárias condições de segurança não têm comprometido o compromisso e a qualidade do trabalho realizado pela instituição, ainda que não se possa atribuir a esta qualidade o mesmo sentido que orienta o SOEC.

Em 2009, a Secretária de Educação do Município do Rio de Janeiro inicia sua gestão mapeando e apresentando diversos dados extraídos de pesquisas da avaliação do Programa Internacional de Avaliação de Alunos (Pisa) ${ }^{2}$ e da Provinha Brasil. Os resultados que assinalavam as dificuldades de leitura e escrita em uma parcela considerável de alunos/as foi uma das justificativas para o projeto que tem sido o carrochefe da gestão da SME/Rio, o Projeto "Salto de Qualidade da Educação Carioca".

\footnotetext{
2 O Pisa, programa internacional de avaliação comparada desenvolvido e coordenado internacionalmente pela Organização para Cooperação e Desenvolvimento Econômico (OCDE), pretende avaliar o desempenho em Leitura, Matemática e Ciências Naturais.
} 
Antes de prosseguir, vamos retomar a discussão em torno do sentido que a SME/ Rio procura atribuir à qualidade quando implementa essas ações. Como afirmamos anteriormente, vários sentidos podem ser atribuídos à qualidade. Portanto, é preciso problematizar o sentido - ou sentidos - que se atribui à qualidade que dá nome e orienta o Projeto Salto de Qualidade da Educação. Cabe indagar: Salto para onde?

No próprio site da SME/Rio encontramos pistas que podem nos permitir responder a esta questão. A proposta se fundamenta na idéia de educação como política pública que precisa ser eficaz.

Segundo material divulgado no site da SME/Rio (RIO DE JANEIRO, 2009), uma política pública eficaz se caracteriza, dentre outras coisas, pela fixação de metas mensuráveis, a partir dos descritores dos problemas (produtos $\mathrm{x}$ resultados); monitoramento e avaliação do processo e dos produtos, resultados e impactos. Nessa perspectiva, o uso das tecnologias tem sido anunciado e apropriado como um dos caminhos pelos quais a obtenção de melhores desempenhos se tornará possível.

Isso fica explícito nos fragmentos a seguir, que foram retirados do site da SME/Rio, em sua proposta de avaliar desempenhos e premiar as instituições bem sucedidas. Tal constatação fica bem explícita durante discurso do Prefeito Eduardo Paes aos pais e docentes presentes à cerimônia de entrega das obras da primeira escola a receber 0 projeto Um Computador por Aluno (UCA) (2010, não paginado) na cidade:

Se tem uma área que só dá alegrias para nós da prefeitura é a de Educação. É bom vir numa escola onde os alunos tiveram esse desempenho fantástico, que é fruto de um processo de avaliação e melhoria. Porque na vida a gente é avaliado o tempo todo, tem que se esforçar e lutar para conseguir o que quer. A vida tem que ser feita de metas e de tarefas a serem cumpridas, porque 0 mundo lá fora é assim, e temos que preparar as crianças para isso e para construir uma cidade melhor.

0 discurso do Prefeito está carregado de sentidos que expressam uma visão administrativa da realidade em sintonia com uma cultura da performatividade. Um discurso que tem a pretensão de organizar e controlar a realidade, forjando comportamentos e atitudes necessários à manutenção de uma determinada ordem, conformando subjetividades às novas exigências sociais. Paralelamente ao reconhecimento das instituições bem-sucedidas, o Prefeito admite a convicção de que a apropriação das novas tecnologias é um dos caminhos pelos quais estes melhores desempenhos podem ser obtidos.

Na investigação também é possivel identificar o uso da privatização como uma tecnologia que favorece as mudanças pretendidas pelo estabelecimento de parcerias entre o setor público e privado, possibilitando a diversificação das atribuições dos 
gestores escolares e a intensificação dos projetos que buscam ser implementados pelas escolas, que exigem que a instituição se envolva em um processo contínuo de reformulação, adequação e acompanhamento, tudo articulado por um discurso em defesa da qualidade da educação concebida como eficiência da escola.

Defendemos, como Ball (2004) que o uso dessas tecnologias se dá com o objetivo de alterar a lógica de funcionamento das escolas. No entanto, procuramos ressaltar que elas precisam ser negociadas com as realidades locais e neste processo são recontextualizadas (BALL, 2004). Por isso o controle sobre as escolas é intensificado de maneira a garantir as metas previamente definidas, embora esse objetivo seja impossivel de ser plenamente alcançado.

Exemplo de tais vínculos puderam ser encontrados no site, por exemplo, quando a SME/Rio firmou, em parceria com o Instituto Oi Futuro e o lbope, no dia 24 de maio de 2010, o desenvolvimento de uma pesquisa para diagnosticar como diretores, coordenadores, professores e alunos da rede municipal se relacionam com as tecnologias de informação e comunicação. Durante a cerimônia, realizada no Teatro Oi Casa Grande, a Subsecretária de Educação disse que a pesquisa é um "chute a gol" para iniciar um grande projeto digital na rede municipal de ensino. Em sua fala, ela garantiu: "Estamos trabalhando para superar os empecilhos físicos das escolas e, assim, alcançarmos a meta de ter todas as unidades da rede com internet sem fio até o fim do ano" (RIO DE JANEIRO, 2010).

É possível identificar no discurso da administração municipal uma tentativa de aproximar o modelo de gestão pública do modelo empresarial privado. A qualidade da educação passa a ser concebida, fundamentalmente, como uma questão de gestão competitiva como em qualquer empresa privada e se sustenta em uma concepção de educação como valor de troca, como um bem privado.

Uma evidência dessa tendência pode ser identificada na intenção de estipular bonificações para as escolas que conseguirem cumprir as metas previamente estabelecidas. Na proposta de um Salto de Qualidade salta aos olhos a perspectiva marcadamente eficientista da gestão pública. É o caso do Prêmio Anual de Desempenho, que também foi matéria de jornal.

A SME/Rio estuda "um plano de premiação de servidores, da educação, com pagamento para todos os funcionários das escolas que atingirem metas estabelecidas. Professores e servidores das escolas que conseguirem atingir as metas recebem o Prêmio Anual de Desempenho" (UMA VERDADEIRA..., 2009, p. 4).

Para participar do programa, as diretoras de todas as escolas da rede municipal assinaram um termo de compromisso que fixava as metas a serem alcançadas por cada unidade escolar. 
No dia 4 de agosto de 2010, o site anuncia que profissionais de 290 colégios municipais contemplados pelo "Prêmio Anual de Desempenho" receberiam até um salário e meio a mais (PREFEITO..., 2010). A matéria indicou o incentivo do Prefeito e da Secretária Municipal de Educação, que participaram da cerimônia de entrega. Obtiveram a premiação as escolas que cumpriram com as metas estipuladas previamente, melhorando seus Índices de Desenvolvimento da Educação Básica (Ideb), medidos através da "Prova Brasil", aplicada pelo Ministério da Educação (MEC) para todos os alunos do $5^{\circ}$ e $9^{\circ}$ anos:

0 prefeito Eduardo Paes e a secretária municipal de Educação, Claudia Costin, participam da cerimônia de premiação das escolas que atingiram as metas e conquistaram o "Prêmio Anual de Desempenho", criado para valorizar e incentivar o trabalho dos profissionais de educação do município. As equipes que alcançaram as metas serão premiadas com um salário a mais. Para os profissionais que trabalham em uma das 150 unidades integrantes do projeto "Escolas do Amanhã", o prêmio será de um salário e meio. Foram contemplados este ano 4.696 professores, 1.558 servidores e 1.798 duplas regências, de 290 escolas da rede, que atingiram as metas estabelecidas no Termo de Compromisso de Desempenho (PREFEITO..., 2010, não paginado).

É possível identificar a existência de semelhanças entre o contrato de gestão das escolas e os modelos privados de aferição de desempenho e destaca que os mentores da área estratégica do governo têm origem no setor privado. A associação da educação com modelos empresariais é uma marca nas ações da gestão municipal. A adoção de critérios de performatividade, de premiação dos melhores desempenhos assume contornos mais fortes também na rede municipal de ensino.

Com relação às novas atribuições que teria que assumir a Diretora da Escola Amanhã revela sua preocupação em entrevista concedida às pesquisadoras:

Agora a ideia deles é cada vez mais fazer do diretor um gestor. Eu não tenho muita prática com isso não, com coisas de dinheiro... desde o tempo da minha mãe, que também foi diretora, a gente nem pegava em dinheiro! Já vinham as coisas todas [...] eu sinceramente não sei muito lidar com isso, eu prefiro muito mais a parte pedagógica (Diretora da escola).

No entanto, embora incomodada com a situação, ela mostrou disponibilidade para se adaptar à situação, interessada em saber sobre instituições que oferecem Cursos de Gestão Educacional: "Eu estou precisando me atualizar nisso... se souber de algum, me avisa!" (Diretora da escola). 
Enquanto a oportunidade de capacitação não surge, a Diretora vai lançando mão de outras estratégias para superar as dificuldades. Uma delas é buscar a colaboração junto aos professores. 0 professor de Educação Física, que também era o responsável por organizar a rádio da escola, tem ajudado com as questões financeiras. É interessante notar como as novas exigências podem sobrecarregar e reorientar o papel da direção na escola, mas também podem criar condições para uma gestão partilhada e democrática.

Com relação às parcerias em curso no âmbito da SME/Rio, elas envolvem entidades contratadas para elaborarem projetos, fornecerem materiais e capacitarem docentes. Algumas envolvem agentes públicos: é o caso da parceria com o Projeto Fundão da Universidade Federal do Rio de Janeiro (UFRJ) voltado para capacitação dos(as) professores(as) de Matemática. Outras envolvem agentes privados, como é o caso da parceria firmada com o Instituto Ayrton Senna (IAS) para a proposta do processo de "Re-alfabetização dos analfabetos funcionais em turmas separadas" (ACELERA).

Essas parcerias são justificadas pela SME/Rio em função dos baixos resultados apresentados a partir do exame aplicado aos alunos e alunas da rede para o levantamento do diagnóstico do nivel de aprendizagem dos(as) mesmos(as). As provas foram aplicadas a estudantes dos $4^{\circ}, 5^{\circ}$ e $6^{\circ}$ anos do Ensino Fundamental para identificar os analfabetos funcionais, que seriam atendidos em turmas separadas. Além disso, todos os 720 mil estudantes da rede fizeram exames de Português e Matemática para estabelecer aqueles(as) que precisariam de aulas de reforço em horário extra.

Ao longo do ano de 2009, os provões bimestrais com conteúdo único para todas as escolas entraram na rotina. 0 objetivo, segundo a Secretaria Municipal de Educação, é avaliar se o currículo escolar de cada série está sendo aplicado igualmente em todas as 1.042 unidades da rede. "A partir daí, vamos dar alunos e professores o apoio que eles precisam para ensinar e aprender em um único e bom nível", afirmou o Subsecretário de Educação Álvaro Crispino (PINHEIRO, 2009, não paginado, grifo nosso).

Esse discurso que reforça o entendimento de uma relação linear e inequívoca entre ensino e aprendizagem - sustentada em uma concepção de currículo como rol de conteúdos cuja transmissão, assentada em metodologias adequadas de ensino - garantiria a aprendizagem. A análise que desenvolvemos nos possibilita afirmar que essa compreensão está pautada em teorias eficienticistas que privilegiam metas pautadas por padrões de desempenho definidos a priori, que têm sido muito questionadas no campo educacional nas últimas décadas, mas que ganham projeção nas ações da SME/Rio.

Na mesma matéria, é exaltado o fato de alunos e alunas dos primeiros anos de alfabetização, de uma determinada escola, já estarem preparados para a maratona de provas. Esse discurso evidencia que a melhoria da qualidade da educação pode ser expressa apenas pelos desempenhos dos alunos, averiguados, é bom que se diga, por instrumentos que 
obedecem a uma lógica de padronização e que expressam sentidos de qualidade da educação associados à resultados que se traduzem em dados mensuráveis e quantificáveis.

O SOEC, com suas ações de intervenção integradas, tem causado forte impacto no cotidiano das escolas em geral, e em especial nas Escolas do Amanhã. Não tem sido diferente na escola pesquisada, que, em função dos resultados apresentados, passou a contar com quatro turmas, vinte e cinco alunos/as em cada, integrando o projeto ACELERA.

Apesar dos esforços para se adaptar às determinações da SME/Rio, a insegurança era grande entre os(as) profissionais da escola, devido à falta de informações, principalmente sobre como o trabalho específico com as turmas seria feito e por quem, já que havia falta de docentes. Na reunião de planejamento realizada no dia 8 de abril de 2009, alguns pontos dos novos projetos já estavam se delineando com mais nitidez. A diretora iniciou sua fala lembrando a inclusão da escola no projeto Escolas do Amanhã, destacando a possibilidade dessa inclusão resultar em maiores recursos para a realização do trabalho e para o atendimento de um maior número de alunos/as.

Durante essa reunião houve um tempo maior destinado à discussão com as professoras que atenderiam as turmas constituídas a partir dos novos projetos da SME/Rio. Além do projeto ACELERA, havia também um novo projeto, o SE LIGA, que tem por objetivo a realfabetização de alunos e alunas do $2^{\circ}$ ao $5^{\circ}$ ano com defasagem idade/série considerados analfabetos funcionais.

0 projeto também utiliza a metodologia e o material produzido pelo IAS, e as aulas de apoio acontecem no turno em que estão matriculados os alunos que dele participam. As turmas também contam com 25 alunos. 0 processo dispõe de orientação e supervisão de uma equipe pedagógica, mas as dúvidas dos(as) professores(as) eram muitas, principalmente sobre qual teria de ser o diferencial para atuarem em turmas compostas por alunos/as com dificuldades de leitura e escrita.

Com o a escola não tinha apresentado resultados muito favoráveis na avaliação da SME/Rio, as professoras das turmas avaliadas assumiam uma posição defensiva, alegando que os/as alunos/as já haviam Ihes chegado com dificuldades. No entanto, não constatamos qualquer questionamento aos instrumentos utilizados pela SME/Rio para chegar aos resultados ou a intenção de padronização das ações. Por outro lado, embora as professoras procurassem se eximir de uma possivel culpabilização pelo resultado insuficiente de seus alunos, o sentimento geral era o da necessidade de adaptação às novas orientações, para obter índices mais favoráveis nas próximas avaliações.

0 fato de fazer parte de uma das cento e cinquenta Escolas do Amanhã foi, durante o ano de 2009, conferindo à escola pesquisada uma visibilidade cada vez maior por parte da Prefeitura. A direção foi convidada pelo Jornal Extra e pela produção do programa 
'Educação em rede" ${ }^{\text {"3 }}$ da Empresa de Multimeios da Prefeitura do Rio de Janeiro (Multirio) para apresentar o Projeto Calculando, desenvolvido pela escola e inspirado no quadro "Soletrando" do programa Caldeirão do Huck da Rede Globo de Televisão.

Durante o programa a diretora aproveitou para divulgar um outro projeto desenvolvido pela escola: a "Rádio Criança", coordenada, por iniciativa própria, pelo professor de Educação Física, com verba recebida pelo Governo Federal. A rádio fazia muito sucesso com as crianças.

Apesar de todos os projetos ditos inovadores, foi possivel perceber que os/as profissionais da escola não identificam alterações significativas na qualidade do trabalho realizado em comparação com o ano anterior. E parece que se ressentem pelo não reconhecimento, por parte do poder público, de um trabalho que já vinha sendo realizado pela escola, e que consideramos essencial para o êxito que a SME/Rio comemora.

Para corroborar este nosso entendimento, recorremos ao depoimento da uma das professoras da escola: "Olha, pra dizer a verdade, eu acho que não está mudando tanto assim não [...] sempre se valorizou a leitura por prazer, sempre fizemos muitos projetos".

De fato, alguns dos projetos desenvolvidos no ano anterior continuavam acontecendo. Como por exemplo, o projeto "Prisma: trabalhando múltiplas linguagens", que tinha por objetivo trabalhar com atividades diversas, tais como o "Correio Poético" e a "Mala Literária", com previsão de realização de um "Sarau Poético" ao final do ano letivo.

No entanto, é fato que todos e todas se ressentem das novas exigências e atribuições, pois se sentem pressionados(as) a atendê-las, o que acaba por alterar o cotidiano da instituição que, via de regra, não percebe essas atribuições como resultado de uma necessidade da escola, mas algo imposto de fora dela e é na ambiguidade desta situação que a escola vai se adaptando e neste processo redefinindo sua singularidade.

Ao tomar conhecimento, também pela imprensa, que a SME/Rio estava realizando um mapeamento de todas as necessidades das escolas integrantes do projeto Escolas do Amanhã de forma a garantir o desenvolvimento das ações com o objetivo de atingir a meta de melhorar os indices educacionais, a diretora mostrou interesse e desconfiança. Afinal, segundo ela, as solicitações feitas à SME/Rio nem sempre eram atendidas a contento. Destacamos que a diretora teve acesso às boas novas através de recorte de jornal que levamos à escola, o que nos pareceu reforçar o sentimento de desconfiança em relação ao anúncio. Na ocasião nos contou como estava se "desdobrando" para dar conta das metas do "Projeto Acelera". Em 2009, a EA contava com quatro turmas integrando o projeto, e uma das docentes responsável precisou tirar licença médica devido ao estresse, o que, segundo a diretora, nunca havia acontecido.

3 0 "Educação em rede" é um canal de comunicação direto entre educadores, famílias e sociedade. 0 programa é exibido na BandRio e no canal 14 da Net. 
Passado algum tempo, a intensificação de projetos e parcerias vinculadas à proposta do SOEC se intensificam cada vez mais. Já em 2011, as premiações e solenidades promovidas pela Prefeitura em parceria com a SME/Rio permaneciam ocorrendo com frequência. Em uma delas, publicada no site, no dia 9 de outubro de 2011, Prefeito e Secretária de Educação participam de homenagem a diretores da rede municipal (PREFEITO..., 2011). Diretores adjuntos e coordenadores pedagógicos também foram homenageados. A matéria inicia fazendo um panorama do que foi desenvolvido do início de 2009 até então, ressaltando o trabalho junto às direções das escolas para ampliar a qualidade do ensino. Para isso, o site informa que as unidades foram reorganizadas de maneira a se ter como foco a aprendizagem dos alunos.

Foram inovações a introdução do currículo único, provas bimestrais, cadernos de apoio pedagógico, reforço escolar e projetos de correção de fluxo, além de avaliações externas. Intensificaram-se a dimensão eficientista da qualidade e a cultura da performatividade na organização e funcionamento das escolas.

Em 2010, 558 escolas beneficiaram-se com mais um salário para todos os funcionários que atingiram as metas estabelecidas no Prêmio Anual de Desempenho. Em 2009, foram premiadas 290 unidades. Na cerimônia de premiação, o Prefeito destacou o investimento em educação como fundamental para o desenvolvimento de uma cidade e cobrou o cumprimento de metas previamente estabelecidas como elemento fundamental para a afirmação do protagonismo docente. E concluiu: "Agradeço imensamente a esses profissionais por este salto que a educação da cidade está dando. Nos últimos três anos, eles deram a alma pelo crescimento dessa cidade. Estejam certos de que vocês terão sempre seus direitos garantidos" (PREFEITO..., 2011, não paginado).

A Secretária de Educação também corroborou com o discurso do Prefeito, atribuindo o suposto êxito do projeto SQEC aos profissionais da rede, que estavam proporcionando mais interesse por parte do alunado pelos estudos. Ela então se dirige aos profissionais presentes no evento: "As crianças estão ficando cada vez mais nas escolas e vocês são os responsáveis por essa mágica. Vocês ajudaram a preparar este cenário de salto na educação" (PREFEITO..., 2011, não paginado, grifo nosso).

Percebemos que, embora a SME/Rio insista em vincular este sucesso às propostas da nova gestão e a adesão dos/as profissionais de ensino a elas, na escola pesquisada, esse compromisso profissional é anterior à posse da atual gestão municipal. A Escola Amanhã já realizava uma educação de qualidade antes da proposta do SOEC. Provavelmente, uma qualidade carregada de outros sentidos que, na perspectiva teórica que adotamos, não foram anulados, ao contrário, permanecem negociados e recontextualizados na dinâmica cotidiana da instituição. E essa compreensão nos permite questionar a política de bonificação por desempenho adotada pela administração municipal para valorizar as escolas que alcancem as metas estabelecidas. A nosso ver, 
qualquer incentivo é muito importante para a estima dos(as) profissionais e dos(as) alunos(as), e pode funcionar como elemento motivador. Premiar as escolas e profissionais que se destacam significa reconhecer seus méritos, o que é ótimo. Mas e aquelas tantas outras que encontram maiores dificuldades para superar seus problemas? Questionamo-nos sobre a eficácia de políticas que, com a premiação, contribuem para o estabelecimento de uma competitividade que pode trazer mais dificuldades àquelas instituições que precisam de investimentos financeiros, políticos e pedagógicos para que possam superar as suas dificuldades.

\section{Referências}

BALL, S. Performatividade, privatização e o pós-Estado do bem-estar. Educação \& Sociedade, Campinas, SP, v. 25, n. 89, p. 1105-1126, set./dez. 2004. Disponivel em: <http://www.scielo.br/pdf/es/v25n89/22613.pdf>. Acesso em: 17 nov. 2009.

BOWE, R.; BALL, S. J.; GOLD, A. Reforming education \& changing schools: case studies in policy sociology. New York: Routledge, 1992.

BURBULES, N. C.; TORRES, C. A. Globalização e educação. Porto Alegre: Artes Médicas, 2004.

BURITY, J. Teoria do discurso e educação: reconstruindo o vínculo entre cultura e política. Revista Teias, Rio de Janeiro, v. 11, n. 22, p. 7-29, maio/ago. 2010.

BRASIL. Ministério da Educação. Um Computador por Aluno (UCA). Brasilia, DF: 2010. Disponivel em: <http://www.uca.gov.br/institucional/projeto.jsp>. Acesso em: ago. 2010.

DIAS, R. E. Ciclo de políticas curriculares na formação de professores no Brasil (1996-2006). 2008. 248 f. Tese (Doutorado em Educação)-Faculdade de Educação, Universidade do Estado do Rio de Janeiro, Rio de Janeiro, 2008.

ESCOLA municipal em vila Isabel é entregue reformada. O Dia, Rio de Janeiro, 2010. Disponivel em: <http://odia.terra.com.br/portal/educacao/html/2010/1/ escola_municipal_em_vila_isabel_e_entregue_reformada_61131.html >. Acesso em: 10 mar. 2011.

LACLAU, E. Universalismo, particularismo y la cuestion de la identidad. In: . Emancipación y diferencia. Lisboa: Difel, 1996. p. 43-119.

. La razón populista. Buenos Aires: Fondo de Cultura Econômica, 2005.

LACLAU, E.; MOUFFE, C. Hegemonía y estrategia socialista. Buenos Aires: Fondo de cultura económica, 2004. 
LOPES, A. C. A qualidade da escola pública: uma questão de currículo?. [Belo Horizonte], 2010. Texto apresentado no âmbito do projeto Pensar a educação, pensar o Brasil. No prelo.

MACEDO, E. F. Currículo e hibridismo: para politizar o currículo como cultura. Educação em Foco, Minas Gerais, v. 8, n. 1; 2, p. 13-30, mar./ago., set./fev. 2003/2004.

. Curriculo e competência. In: LOPES, A. C. R.; MACEDO, E. (Org.).

Disciplinas e integração curricular: história e políticas. Rio de Janeiro: DP\&tA, 2002, p. 115-143.

PINHEIRO, A. Exame identificará analfabetos funcionais, O Dia On Line, Rio de Janeiro, 6 mar. 2009. Educação. Disponível em: <http://odia.terra.com.br/educacao/ htm/provao_municipal_na_terca_feira_234141.asp.>. Acesso em: 10 mar. 2009.

PREFEITO e secretária de Educação participam de homenagem a diretores da rede municipal. Educação, Rio de Janeiro, 9 out. 2011. Disponivel em: <http://www.rio.rj. gov.br/web/guest/exibeconteudo?article-id=2199378>. Acesso em: 12 out. 2011.

PREFEITO premia os professores das escolas que atingiram metas de desempenho. Gabinete do Prefeito, Rio de Janeiro, 4 ago. 2010. Disponivel em: <http:// www.rio.rj.gov.br/web/gbp/exibeconteudo?article-id=1008044>. Acesso em: 11 set. 2010.

RIO DE JANEIRO (RJ). Secretaria Municipal de Educação. Projeto Salto de Qualidade na Educação Carioca. Rio de Janeiro, 2009. Disponível em: <http:// www.rio.rj.gov.br/web/sme>. Acesso em: 30 dez. 2009.

SME investe na relação entre a escola e a tecnologia. Educação, Rio de Janeiro, 24 maio 2010. Disponivel em: <http://www.rio.rj.gov.br/web/sme/ exibeconteudo?article-id=820935 >. Acesso em: 11 set. 2010.

TURA, M. L. R. Conhecimentos escolares e a circularidade entre culturas. In: LOPES, A. C. R.; MACEDO, E. (Org.). Currículo: debates contemporâneos. São Paulo: Cortez, 2002, p. 150-173.

UMA VERDADEIRA aula de autoestima. Projeto muda a postura de alunos do município com a realfabetização. O Globo, Rio de Janeiro, 13 dez. 2009. Primeiro Caderno, p. 15.

Recebido em: 27/04/2010

Aceito para publicação em: 03/11/2011 
PEREIRA, Talita Vidal; SEIXAS, Luciana Velloso da Silva. Um salto para performatividade: sentidos atribuídos à qualidade da educação. Ensaio: aval. pol. públ. Educ., Rio de Janeiro, v. 20, n. 74, p. 73-88, jan./mar. 2012.

\begin{tabular}{|c|c|c|c|}
\hline Página & Linha & Onde se lê & Leia-se \\
\hline 73 & Linha 5 (cabeçalho) & Luciana Velloso da Silva Seixas & Luciana Velloso** $^{*}$ \\
\hline
\end{tabular}

